\title{
UMA HISTÓRIA DA VILA HOLÂNDIA POR MEIO DOS DIVERTIMENTOS DE SEUS MORADORES ${ }^{1}$
}

Recebido em: 13/08/2013

Aceito em: 15/02/2014

\author{
Flávia da Cruz Santos ${ }^{2}$ \\ Universidade Federal de Minas Gerais \\ Belo Horizonte $-\mathrm{MG}-$ Brasil \\ Henrique Okajima Nakamoto ${ }^{3}$ \\ Sílvia Cristina Franco Amaral ${ }^{4}$ \\ Universidade Estadual de Campinas \\ Campinas - SP - Brasil
}

RESUMO: Este trabalho tem como objetivo narrar uma história da Vila Holândia a partir dos divertimentos de seus moradores. Descrevemos o modo como este bairro, localizado no distrito de Barão Geraldo, cidade de Campinas (SP), vem se constituindo e se transformando desde sua origem, no que se refere aos seguintes aspectos: organização do espaço físico; relações de vizinhança; e formas de divertimento localmente praticadas. Utilizamos, como material empírico, relatos de moradores obtidos por meio de entrevistas com o método da história oral, realizadas entre os anos de 2009 e 2011. Com base neste material, reconstruímos uma história da Vila a partir das memórias dos próprios moradores e buscamos subsidiar possíveis ações voltadas ao desenvolvimento do lazer no bairro, para que levem em conta as particularidades locais explicitadas a partir da empiria.

PALAVRAS CHAVE: Atividades de Lazer. História. Jogos e brinquedos.

\section{A HISTORY OF VILA HOLÂNDIA THROUGH THE ENTERTAINMENT OF ITS RESIDENTS}

ABSTRACT: This paper aims to tell one history of Vila Holândia based on the amusements of its residents. We describe how this neighborhood, located at the district of Barão Geraldo, Campinas (SP), has been constituted and transformed since its origin, regarding to the following aspects: geographical space organization; neighborhood

\footnotetext{
${ }^{1}$ Pesquisa financiada pela FAPESP.

${ }^{2}$ Mestre em Educação Física pela Universidade Estadual de Campinas. Doutoranda do Programa de PósGraduação Interdisciplinar em Estudos do Lazer da UFMG. Membro do Grupo de Estudos e Pesquisa em Políticas Públicas e Lazer da FEF/UNICAMP.

${ }^{3}$ Mestre em Educação Física pela Universidade Estadual de Campinas. Membro do Grupo de Estudos e Pesquisa em Políticas Públicas e Lazer da FEF/UNICAMP.

${ }^{4}$ Professora livre docente da FEF/UNICAMP. Líder do Grupo de Estudos e Pesquisa em Políticas Públicas e Lazer da FEF/UNICAMP.
} 
relationships; and locally grown amusement forms. We used residents' reports as empirical material, which we obtained from 2009 to 2011 with interviews applying oral history method. Based on this material, we reconstructed one history of Vila Holândia from the memories of the residents themselves and sought to contribute to the implementation of projects for the development of leisure in this neighborhood, so that they consider the local peculiarities evidenced from the empirical.

KEYWORDS: Leisure Activities. History. Play and Playthings.

\section{INTRODUÇÃO}

Nos anos de 2007 e 2008, o "Grupo de Estudos e Pesquisa em Políticas Públicas e Lazer" da Faculdade de Educação Física da Unicamp desenvolveu o Projeto de Extensão Universitária "Lazer Itinerante" na Vila Holândia, localizada no distrito de Barão Geraldo, cidade de Campinas/SP. Tal projeto, que consistia na organização e realização de atividades de lazer junto a moradores da comunidade em finais de semana, trouxe-nos inquietações que inicialmente provocaram mudanças em seu formato e posteriormente levaram à sua extinção. Pois percebemos que ele não dava conta da complexidade que envolvia o lazer em tal comunidade, uma vez que nossas ações eram pontuais, descontínuas e partiam do nosso entendimento, do nosso olhar sobre a vida dos moradores de tal bairro, e não de seus próprios entendimentos, desejos e necessidades.

Paralelamente, percebemos também as transformações ocorridas na Vila e em seu entorno decorrentes da exploração imobiliária, visando à construção de condomínios residenciais de luxo. Passamos a nos perguntar sobre as possíveis influências que tais transformações têm exercido sobre os usos do tempo livre dos moradores da Vila. Essa exploração tem expropriado os espaços para as práticas vividas durante o tempo livre de trabalho e, consequentemente, afetado a vida comunitária local?

Tais percepções e questões nos levaram a desenvolver a pesquisa que ora 
apresentamos, por evidenciarem que o conhecimento da história da Vila, por meio do trabalho com a memória, é importante para a compreensão de suas transformações e das consequências destas para os usos do tempo livre de trabalho de seus moradores. Compreensões estas fundamentais ao desenvolvimento de ações, sejam projetos de extensão universitários ou políticas públicas, capazes de contribuir para a construção da cidadania.

Escolhemos como metodologia de pesquisa a história oral, por sua adequabilidade aos objetivos e à perspectiva do estudo de privilegiar a subjetividade dos processos de rememoração e escrita. Na história oral, leva-se em conta que o narrador, ao compartilhar suas memórias com o pesquisador, o faz de acordo com a relevância para si mesmo, no presente, daquilo que narra. Ao lembrar, ele dá novos significados ao que conta (SIMSON, 2003b). Deste modo, a história construída a partir de tais relatos se constitui como algo capaz de expressar necessidades e identidades atuais dos moradores. Assim, o método abrange técnicas que permitem uma maior - apesar de nunca total liberdade dos entrevistados na condução de seus relatos, possibilitando que versões particulares sejam construídas a partir das escolhas de quem as narra, quanto ao que deve ser contado e ao que deve permanecer silenciado. Nesse sentido, adotamos a técnica denominada "depoimento oral", no qual a entrevista se divide em momentos que variam do relato mais livre, ao mais dirigido. A intenção é identificar se os temas aparecem de forma mais dirigida ou mais espontânea e, a partir daí, analisar os significados que permeiam essa distinção e que ultrapassam o conteúdo das falas.

Dividimos cada entrevista em três momentos, compondo uma estrutura ramificada, na qual os itens de cada momento, a partir do segundo, eram especificações do momento anterior. No primeiro, perguntamos sobre os usos do tempo livre de 
trabalho do entrevistado, ao longo do tempo em que vive na Vila. No segundo, indagamos de maneira direta sobre: divertimentos, espaços de convívio, redes de relacionamento e transformações na Vila Holândia. E, por fim, abordamos lugares, redes de relacionamento, práticas e transformações específicas que já eram de nosso conhecimento.

Escolhemos nosso primeiro informante a partir do critério maior tempo de residência na Vila. Identificamos o morador mais antigo da Vila Holândia, e o tivemos como primeiro informante. Coincidentemente esse morador era também o mais idoso da Vila. A partir daí, identificamos os demais entrevistados através da análise da entrevista anteriormente realizada, seguindo o mesmo critério de maior tempo de residência na Vila (LANG et al, 1998). Assim, cada entrevistado indicava qual seria o nosso próximo interlocutor. Entrevistamos seis pessoas, três mulheres e três homens, moradores antigos da Vila, cujas idades eram 43, 51, 66, 69, 70 e 90 anos ${ }^{5}$.

O que os moradores da Vila Holândia faziam em seu tempo livre de trabalho, se é que faziam algo? Essa foi a nossa primeira questão, cuja resposta balizou o desenrolar de toda a pesquisa. Esse tempo da vida dos moradores é destinado aos divertimentos, desde sempre, desde que a Vila passou a existir, é o que nos disseram todos os nossos interlocutores.

Assim, narraremos neste texto uma história da Vila Holândia a partir dos divertimentos de seus moradores, descrevendo o modo como ela vem se constituindo desde sua origem, no que se refere aos seguintes aspectos: a organização do espaço físico, as relações entre as pessoas e as formas de divertimento e de encontro, compreendidos a partir do olhar e das memórias dos próprios moradores, oferecendo

\footnotetext{
${ }^{5} \mathrm{O}$ consentimento livre e esclarecido dos sujeitos foi obtido e o estudo foi aprovado pelo Comitê de Ética em Pesquisa da Faculdade de Ciências Médicas da UNICAMP.
} 
assim, subsídios ao desenvolvimento de ações para o desenvolvimento do lazer na Vila que levem em conta as particularidades locais explicitadas a partir da empiria.

\section{UMA HISTÓRIA DOS DIVERTIMENTOS NA VILA HOLÂNDIA}

Na década de 1940, algumas fazendas localizadas em Campinas passavam por um processo de desmembramento e venda, devido à crise do café. Nesse contexto, Bastian Krowuel, holandês que se mudou para o Brasil na década de 1920, comprou terras localizadas no então vilarejo de Barão Geraldo. Segundo Maria Adriana, de 70 anos de idade, filha de Bastian Krowuel, na década de 1960, sem interesse de trabalhar com plantações, seu pai loteou e vendeu a maior parte do terreno, ficando apenas com o suficiente para desfrutar do lazer com sua família.

Muitos dos primeiros compradores desses lotes ainda moram na Vila Holândia e, na época da aquisição, já eram moradores ou trabalhadores dos arredores do sítio de Bastian. Possuíam relações com o local e uns com os outros, sejam elas relações de parentesco ou de amizade. Segundo Dona Palmira Baldin, de 90 anos, uma das moradoras mais antigas da Vila: "Era tudo gente conhecida, todo mundo morava por perto, e resolveu comprar" 6 .

Instalados os primeiros moradores, a Vila Holândia foi se constituindo como tal: o espaço físico foi mudando, os terrenos repletos de mato foram sendo ocupados por casas, mais pessoas foram chegando, relações foram sendo construídas. O que os moradores da Vila faziam em seu tempo livre de trabalho? Essa foi a primeira questão colocada aos nossos interlocutores. E a resposta foi unânime: se divertiam, "era lazer". As nossas questões, então, se ampliaram: como os moradores da Vila se divertiam?

\footnotetext{
${ }^{6}$ Entrevista realizada em 10/04/2011.
} 
Como os divertimentos desses moradores foram mudando ao longo do tempo, se é que mudaram? O que essas mudanças revelam?

Três foram as práticas citadas por nossos interlocutores como os principais divertimentos vividos pelos moradores da Vila: as festas, o jogo de bocha e o futebol. Atividades estas que reuniam grande parte dos moradores não apenas no seu desfrute, mas também em sua organização, e que foram desaparecendo com o passar do tempo, por motivos diversos, como a morte e mudança de lideranças locais, a chegada de novos moradores, a perda de apoios políticos e de espaço físico e as brigas entre moradores, como veremos a seguir.

"Basicamente era festa, o povo aqui gosta", afirmou a entrevistada Maria Adriana Krowuel ${ }^{7}$, sobre as atividades de lazer de antigamente, dando destaque às festas de natal, juninas, comemorações de dia das crianças e bailes de carnaval, além de bingos e churrascos, que ocorriam na década de 1970, em propriedades de moradores, no campo de futebol e em terrenos baldios.

Maria Poggetti, Maria Adriana Krowuel, Júlio Davi e Palmira Baldin, enfatizaram diversos aspectos referentes aos trabalhos de preparação de tais festas, com destaque ao caráter voluntário das iniciativas. "Era tudo grátis, era a gente que dava, cada um ajudava como podia" ${ }^{8}$. Dentre os envolvidos, Maria Projete (de 69 anos de idade) destacou a participação de vários moradores e moradoras, alguns dos quais haviam sido presidentes da Associação de Moradores da Vila Holândia, e também vereadores que contribuíam com dinheiro, pão, carne, entre outras coisas. Uma divisão do trabalho por gênero pôde ser notada nos relatos, com destaque às funções femininas, envolvendo a arrecadação de prendas e o preparo de pizzas, bolos e outros quitutes.

\footnotetext{
${ }^{7}$ Entrevista realizada em 25/11/2009.

${ }^{8}$ Entrevista com Maria Poggetti, realizada no dia 04/12/2009.
} 
Maria Poggetti recordou tais ocasiões com entusiasmo:

\begin{abstract}
Sempre quem trabalhava era eu, a Sofia, a Adelina, a Ana Amaral. Ah, tinha a turminha boa para trabalhar. [...] A gente trabalhava, saía para pedir prenda pelos sítios, ganhava galinha, ganhava de tudo. Até leilão tinha na nossa festa! [...] Meu filho caçula era pequenininho, a minha filha tomava conta e eu trabalhava na organização. Tinha que vim de lá meia noite, uma hora. [...] Fazia as coisas aqui em casa e levava (Entrevista com Maria Poggetti realizada em 22 de março de 2011).
\end{abstract}

Episódios específicos foram rememorados, tais como uma festa de dia das crianças que, por falta de outro local, foi realizada no campo de futebol; a presença da bandinha de música de Campinas em uma das festas; e as matinês de carnaval que, por falta de iluminação pública, ocorriam em um barracão desativado. Segundo relato da própria moradora, “[...] fazia baldes e baldes de ki-suco. Alguém dava alguma coisa, alguma pipoca, qualquer coisa, então fazia matinê de carnaval. A criançada se esbaldava. Vinha tudo para cá" 9 .

No relato de Maria Poggetti, talvez pelo grande envolvimento de seu marido Oswaldo Poggetti com as questões políticas da Vila Holândia - ele fora presidente da Associação de Moradores - percebe-se grande ênfase na contribuição de vereadores no atendimento de demandas da Vila, inclusive referentes ao lazer. Ela mencionou um vereador de Paulínia, já falecido:

Ele ajudou muito aqui no bairro, nossa, tanto nas festas quanto o povo daqui também. [...] Ele ajudava muito né. Até carne, essas coisas, ele dava. A gente queria fazer uma festa para as crianças, dia das crianças, a carne moída para fazer lanche, essas coisa, ele dava tudo (Entrevista com Maria Poggetti realizada em 22 de março de 2011).

Segundo a entrevistada, o vínculo da Vila e de seus moradores com a cidade

\footnotetext{
${ }^{9}$ Entrevista com Maria Adriana Krowuel, realizada em 23/03/2011.
} 
vizinha, Paulínia, justificava o interesse do vereador. "O povo daqui votava muito lá em Paulínia. A turma daqui votava tudo nele. [...] Porque tudo que precisava era ele" ${ }^{10}$. Além disso, Maria Poggetti deu grande ênfase ao vínculo entre as festas e a Associação de Moradores. Segundo ela, o objetivo das festas e bingos era arrecadar dinheiro para a construção da Associação, que tinha como objetivo principal possibilitar melhorias ao bairro.

O mesmo vínculo entre festas, Associação e busca de melhorias para o bairro é ressaltado por Maria Adriana Krowuel, que disse da importante atuação de Oswaldo Poggetti.

\begin{abstract}
Tinha o seu Oswaldo Poggeti também, que era muito engajado nessas coisas. Ele era muito festeiro também, e muitos moradores que até hoje estão aí. [...] Todos têm chácara aí, e eles trabalharam muito, fizeram muita coisa, muita festa. Inclusive, teve até um postinho de saúde uma época. [...] Foram feitos bingos pra ajudar gente que precisava financeiramente pra tratamento de saúde. Foi feito bingo, se arrecadava prenda, o povo todo ia, e essa renda ia para um rapaz que tava com leucemia. Inclusive esse rapaz já morreu. [...] Foi feito feijoada, foi feita muita coisa, porque o povo aqui é muito solidário. (Entrevista com Maria Adriana Krowuel realizada em 25 de novembro de 2009).
\end{abstract}

No entanto, Maria Adriana deu ênfase também ao sentido hedonístico, não utilitário das festas como práticas de lazer, e da própria Associação como espaço de lazer, criado na década de 1970, como uma "sociedade de amigos do bairro", um espaço próprio para a realização das festas que floresciam naquela época.

Ambas as entrevistadas, Maria Poggetti e Maria Adriana, explicitaram o vínculo entre as festas e a Associação de Moradores. No entanto, enquanto na fala da primeira ressalta-se a busca por melhorias no bairro, em função da qual a Associação foi construída e as atividades festivas eram realizadas, na fala da segunda destaca-se a

\footnotetext{
${ }^{10}$ Entrevista com Maria Poggetti, realizada em 22/03/2011.
} 
vocação dos moradores para festas, e estas como fator motivador da formação e construção da Associação.

Os relatos contradizem um ao outro em relação ao surgimento das festas que, segundo Maria Poggetti, passaram a ocorrer com o objetivo de arrecadar dinheiro para a compra do terreno e construção da Associação, mas que segundo Maria Adriana, já ocorriam antes e independentemente da Associação, criada posteriormente para abrigar o lazer da Vila. Versões contrastantes, talvez relacionadas ao fato de a primeira entrevistada morar na Vila e de seu marido ter tido um envolvimento na política local, e de a segunda, naquela época, apenas frequentar o local em seus momentos de lazer ${ }^{11}$. Versões, porém, complementares, que mostram diferentes facetas e significados não excludentes de uma comunhão comunitária que florescia no local há décadas atrás.

Outro aspecto a ser ressaltado acerca das festas é a importância conferida, por ambas as moradoras, à contribuição de Sofia Krowuel, filha de Bastian Krowuel e irmã de Maria Adriana. "Ela fazia muita coisa. Ela fazia canjica. Pizza a gente fazia na hora, para o povo. Ela que fazia tudo. Era pizza, era cachorro quente, era churrasquinho. Era bem organizado" 12 .

No mesmo sentido, Júlio Davi, de 66 anos, marido de Maria Adriana, afirmou: "Essa Dona Sofia aí, chegava a fazer mais de cem, cento e poucas pizzas numa noite" 13. Maria Adriana mencionou que, apesar de não morarem na Vila:

A Sofia sempre gostou muito, é o que eu falo, ela sempre se doou muito.

\footnotetext{
${ }^{11}$ Segundo a moradora: “... isso aqui (a casa onde mora hoje, na Vila) também nunca foi moradia do meu pai. Sempre foi pra... ele tinha o lazer dele, e tinha aí. Às vezes ele alugava, arrendava para alguém. Isso aqui teve criação de frangos, na época que era do meu pai mesmo, galinha. E teve criação de porcos, que meu pai também fez isso. Mas depois ele sempre arrendava. Ele nunca dependeu disso porque ele tinha a carpintaria. A primeira pessoa que mora aqui, realmente, sou eu. Que faz, em abril, seis anos". (Entrevista com Maria Adriana Krowuel realizada em 23/03/2011).

${ }^{12}$ Entrevista com Maria Poggetti, realizada em 22 de março de 2011.

${ }^{13}$ Entrevista com Júlio Davi realizada em 23/03/2011.
} 
Então, com qualquer pessoa que você conversar, dos antigos da Vila Holândia, põe ela no altar. Porque ela sempre se interessou em ajudar o próximo (Entrevista com Maria Adriana Krowuel realizada em 23 de março de 2011).

Adilson Baldin, de 51 anos de idade, acrescenta à presente descrição memórias de quem experienciou a época das festas como criança e adolescente, dando destaque às festas juninas. Adilson recordou com entusiasmo o churrasco, o quentão, a pipoca, os jogos e brincadeiras típicas como a cadeia, o jogo de argolas, o correio elegante, entre outras atividades que, apesar de organizadas pelos adultos, eram conduzidas pelas próprias crianças. $\mathrm{O}$ entrevistado chamou a atenção para a união que existia entre os moradores para organizar as festas e outras práticas. Ressaltou que as mesmas pessoas envolvidas com o futebol estavam envolvidas também com o bocha, com as festas e com a Associação, o que transformava a Vila em uma verdadeira comunidade, marcada por uma intensa participação dos moradores. “O mesmo pessoal que estava lá no campo estava aí à noite, nas festas. [...] Você jogava bola no domingo à tarde e ia em casa, tomava banho e se encontrava com todo mundo na festa também" ${ }^{14}$.

A nostalgia presente nos relatos sobre as festas foi proporcional aos lamentos acerca da decadência das mesmas, por parte de todos os entrevistados. Sobre os motivos do fim das festas, são várias as hipóteses dos entrevistados. Uma delas é a morte e evasão de lideranças que organizavam a vida social da Vila, entre eles, Sofia Krowuel e Oswaldo Poggeti. Maria Adriana disse que a saída de Sofia da Vila, que se mudou para outra cidade "prejudicou bastante. Ela fazia muita coisa." ${ }^{15}$. A morte de Oswaldo Poggetti também repercutiu negativamente no lazer da Vila:

\footnotetext{
${ }^{14}$ Entrevista com Adilson Baldin realizada em 20/05/2011.

${ }^{15}$ Entrevista com Maria Adriana Krowuel realizada em 23/03/2011.
} 
Enquanto meu marido estava vivo, e ele pagava a conta lá, ainda tinha. Ele pagava tudo, a conta, fazia bingo, essas coisas, pra poder pagar água, luz, imposto. Mas depois que ele caiu doente a turma abandonou, ninguém mais fez. Já vai fazer seis anos. [...] Ninguém deu sequência, tá tudo parado. (Entrevista com Maria Poggetti realizada em 22 de março de 2011).

Segundo Maria Poggetti, a morte de Oswaldo Poggetti teve como consequência a perda do contato da Vila com o governo. "Não deu mais pra ir atrás. Acabou o movimento. Meu marido precisava das coisas na prefeitura, ligava lá pro Flores, o Flores adiantava tudo..." ${ }^{16}$. Além disso, a perda deste importante vínculo estaria, segundo a entrevistada, associada à morte de um dos vereadores que atendiam às necessidades da população local e ao fato de que "agora a gente não pode mais votar em Paulínia" ${ }^{17}$, indicando o possível motivo da perda de interesse dos políticos deste município pela Vila.

Outro motivo apontado como causa do fim das festas foram as diferenças entre gerações. Por um lado, o perfil participativo de antigamente e, por outro, o atual desinteresse da população. "Nessa época de festa, nossa, eles ajudavam demais. Davam o sangue, era muito, era muito participativo. O povo era muito bom" 18 . "Hoje mudou completamente, né? Hoje a união, comparando com a união que tinha há vinte anos atrás, hoje não tem nada." 19 . "No começo vinha um monte de gente trabalhar, mas agora, você faz uma festinha, faz um bingo, são três ou quatro que trabalham só" 20 .

Segundo Adilson, as festas acabaram, pois a nova geração não assumiu o que a geração antiga havia construído. Para o entrevistado, a mentalidade dos jovens, dentro e fora da Vila, mudou e estes não têm mais o interesse e a determinação que os mais antigos tinham para fazer tais festas, manter as amizades e as atividades. Afirmou o

\footnotetext{
${ }^{16}$ Entrevista com Maria Poggetti realizada em 22/03/2011.

17 Ibid.

${ }^{18}$ Entrevista com Maria Adriana Krowuel e Júlio Davi Gonçalves realizada em 23/03/2011.

${ }^{19}$ Entrevista com Adilson Baldin realizada em 20/05/2011.

${ }^{20}$ Entrevista com Maria Poggetti realizada em 04/12/2009.
} 
entrevistado:

\begin{abstract}
Quem cuidava muito disso aí eram os mais antigos. Os antigos, acho que eles se preocupavam, eles trabalhavam mais, eles faziam mais. Depois, quando o pessoal foi se acabando, eu acho que o que veio, assim, os filhos, eu acho que não pegou, sabe? Essa determinação que esse pessoal tinha. E eu acho que as amizades também eram mais sinceras, o pessoal era melhor, tinha mais fundamento. Hoje é muito diferente, hoje as amizades são muito falsas. Então, eu acho que mudou muito, sabe? De um modo geral eu vejo que não só aqui como por aí também. Uma festa inclusive, uma festa de Betel ${ }^{21}$, hoje não tem uma festa em Betel como que tinha antes, há uns anos atrás (Entrevista com Adilson Baldin realizada em 20 de maio de 2011).
\end{abstract}

As percepções de Adilson são corroboradas por Caldeyro (2005), que nos ajuda a compreender a intensa vida comunitária da Vila Holândia em seus primórdios. Ela descreve o vilarejo de Barão Geraldo, de 1953 a 1970, como tendo um desenvolvimento do comércio e da infraestrutura pautado em "redes de compadrio", por uma estrutura política local e por uma identidade baronense, formada pelo pertencimento a uma rede de relacionamentos local.

Tais elementos, a partir da década de 1970, entraram em declínio refletindo no lazer local. As implantações da Unicamp e do Centro Médico aceleraram o processo de urbanização de Barão Geraldo, caracterizado por fatores que se inter-relacionam: a chegada de famílias de médio e alto poder aquisitivo, para as quais condomínios foram criados, a concentração de atividades culturais, a intensa vida acadêmica, o aumento da população flutuante, e a expansão do comércio e de serviços específicos como o de hospedagem. Barão Geraldo, assim, tornou-se um distrito universitário, cuja população predominante possui "características econômicas, sociais e culturais bastante diferenciadas dos moradores da até então Barão Geraldo" (CALDEYRO, 2005, p. 24).

Esse processo de urbanização de Barão Geraldo gerou um novo movimento

${ }^{21}$ Bairro do município de Paulínia. 
ocupacional na Vila Holândia, trazendo uma população com um perfil distinto em relação aos antigos moradores, prejudicando a coesão entre eles e, consequentemente, a realização de festas e de outras ações coletivas. O progresso de Barão Geraldo também levou à dispersão da vida comunitária na Vila Holândia por facilitar o acesso a outros espaços e outras práticas.

De forma recorrente nas entrevistas, os moradores, ao serem questionados sobre o fim das festas, disseram de sua relação com o fim da Associação, pela posição central que ela ocupava na vida comunitária local. Este vínculo entre lazer e política nos leva à hipótese de que, para além da oposição entre "interessados" e "desinteressados" em participar e contribuir ao desenvolvimento da Vila, disputas por poder parecem ter desgastado a relação entre moradores, gerando rupturas que afetaram o lazer. $\mathrm{O}$ caso relatado por Júlio, quando moradores contrários à sua participação na Associação, apelaram para sua exterioridade, como forma de deixá-lo fora das decisões, exemplifica bem o acirramento desta disputa. "Teve umas eleições aí, pra sociedade, que o cara me proibiu de votar" 22 .

Contudo, o conflito mais recorrentemente citado, como causa do atual abandono da Associação, ocorreu quando da tentativa de reconstruir a prática do jogo de bocha que, em meados da década de 1970, ocorria em uma cancha instalada em um armazém, hoje desativado. Segundo Adilson, o armazém servia como ponto de encontro dos moradores da Vila, sendo a cancha, comum neste tipo de estabelecimento, “[...] uma atração da Vila naquela época" ${ }^{23}$, que reunia os homens aos finais de semana, em torneios contra equipes de Barão Geraldo, Paulínia e de outras cidades da região. Adilson, na época adolescente, conta ter trabalhado no armazém e participado com seu

\footnotetext{
${ }^{22}$ Entrevista com Júlio Davi realizada em 23/03/2011.

${ }^{23}$ Entrevista com Adilson Baldin, realizada em 20/05/2011.
} 
pai e com os moradores mais velhos de tais torneios. $\mathrm{O}$ bocha era jogado por homens mais velhos, com cerca de cinquenta anos, porém os jovens, segundo o entrevistado, “[...] acabavam indo no embalo" ${ }^{24}$. Esta prática acabou quando o dono do armazém, que era também quem organizava os jogos, faleceu.

Décadas depois, a ideia de construir um campo de bocha na Associação de Moradores da Vila Holândia animou os moradores a reativarem o local. Contas atrasadas foram pagas, o prédio foi reformado e o campo foi construído, com a ajuda de um vereador conhecido do morador Oswaldo Poggetti, presidente da Associação naquele momento, dando início ao que os moradores Júlio Davi e Adriana Krowuel afirmaram ter sido "o segundo período da antiga Associação". Um período marcado, segundo Adilson, pelo convívio familiar neste espaço de lazer, onde aconteciam, além do bocha, jogos de futebol, festas, churrascos e bingos, estes últimos visando a contribuir com o pagamento das contas do local e a ajudar moradores do bairro que passavam por dificuldades financeiras.

No entanto, a proximidade da Associação com as casas começou a gerar problemas. O mesmo bocha que serviu como fator motivador para a reativação da Associação se tornou, por conta do barulho das bolas nas tábuas, motivo de reclamações junto à prefeitura de Campinas e de brigas entre os moradores. "E aí começou, sabe? Virou uma bola de neve. E aí é a prefeitura, a polícia, vinha intimação, a gente conseguia tirar a intimação e voltava, entendeu? Aí eles vinham de novo" ${ }^{25}$. Tal fato não apenas culminou no fechamento do local, mas parece ter deixado uma ferida na rede de relações, prejudicando o convívio e a cooperação comunitários, e a comunicação com o governo local, para a busca por melhorias, incluindo aquelas

\footnotetext{
${ }^{24} \mathrm{Ibid}$.

${ }^{25}$ Ibid.
} 
referentes ao lazer, e contribuído para uma mudança no perfil engajado dos moradores da Vila, que passaram a buscar lazeres mais particulares:

\begin{abstract}
Muita encrenca, confusão. Aí, pra não acontecer coisa pior, o pessoal deixou de participar, deixou de vir, entendeu? Aí o negócio foi acabando, acabando e a gente falou: Poxa, eu ficar dando murro em ponta de faca? Então eu vou partir pro meu lazer, eu vou buscar uma outra coisa pra mim e pra minha família. E acabou deixando isso aí, e virou isso aí. Hoje está abandonado. [...] Meu moleque ia jogar bola, a gente ia jogar bocha, a gente participava de bingo, a Sílvia (esposa de Adilson) trabalhava, fazia pastel, festinhas. Era um lugar de lazer. Aos sábados o pessoal vinha, o pessoal gosta de jogar bingo e tal. E... acabou. Então, agora, porque eu vou ficar aí correndo atrás dessas coisas? Então, meu moleque vai lá no clube da Rhodia. E eu vou pescar, tem rancho lá em Jaguariúna e eu vou pra lá. Entendeu? Agora, por que eu vou ficar aí, querendo fazer alguma coisa pro pessoal e o pessoal, alguns aí, por causa de vizinho, quer confusão, briga, xinga daqui e de lá? (Entrevista com Adilson Baldin, realizada em Maio de 2011).
\end{abstract}

Outro fator que contribuiu para o enfraquecimento da rede de relações foi a evasão e a chegada de moradores na Vila e em seu entorno. Tentando explicar a evasão de moradores Maria Adriana Krowuel disse que "quem casa quer casa. Já compra em outro lugar e foi... foi saindo" ${ }^{26}$. Maria Poggetti corroborou esta perspectiva, mencionando que "muitos foram para Paulínia, quando saíram aqueles loteamentos, compraram, foram para lá, foram embora" ${ }^{27}$. Adilson apresenta algumas hipóteses para a evasão de moradores:

Eu creio que mais ou menos cinquenta, sessenta por cento. Foi mais ou menos metade, metade desse pessoal continua aqui e metade tá, assim, para fora. O pessoal casou com outras meninas de uma outra região, então acabou indo morar em outro lugar. Ou mesmo foram para outras empresas, melhorias, essas coisas aí. Porque, às vezes, tem alguns aqui que não são proprietários, entendeu? Acabaram indo embora, arrumando alguma coisa melhor. Eu acho que quem ficou mesmo era mais proprietário ou família menor, por exemplo, família grande acabou vendendo, cada um tomou o seu rumo (Entrevista com Adilson Baldin realizada em 20 de maio 2011).

\footnotetext{
${ }^{26}$ Entrevista com Maria Adriana Krowuel realizada em 23/03/2011.

${ }^{27}$ Entrevista com Maria Poggetti realizada em 22/03/2011.
} 
O desenvolvimento industrial e tecnológico de Paulínia e de Barão Geraldo gerou novos empregos, em geral, de baixa renda, e trouxe novos moradores para a Vila, que formaram núcleos residenciais em casas alugadas, que abrigam várias famílias, chamados por alguns moradores de "cortiços" e "favelas". Um entrevistado mencionou o perfil étnico diferenciado da nova população: "Foi quando montou a Petrobrás que começou com a gentarada feia vindo para cá” [...]. Vem Maranhense, Paraense, Pernambucano, vem de tudo quanto é lado". A chegada de novos moradores foi justificada da mesma forma por mais um entrevistado: "Barão Geraldo, Campinas, Cosmópolis, Paulínia, é um pólo petroquímico hoje essa região. Tem a Petrobras, Rhodia, então acaba acarretando muitas empreiteiras. Então acaba vindo muita gente de fora. Vem para trabalhar".

Os entrevistados expressaram ora indiferença, ora sensibilidade acerca da situação vivida por esta nova população:

\footnotetext{
Você quer ver encher a igreja de gente, é você falar que vai ter um bolo. Que vai ter um bolo, um guaraná, um salgadinho. Nossa, entope. Mas é um monte de criancinhas também, né. Que criancinha é carente, dá dó, né. [...] Eles são carentes. Tão carentes que precisaria ter alguma coisa.
}

Mas o que prevalece na fala dos entrevistados, cujas identidades optamos por manter em sigilo, é a ideia da segregação: "Então, é um povo que precisa, mas... que não tem condição de você conviver". "E daí acabou tudo. Hoje, você faria um negócio desses? Com a molecada que não tem berço, não tem educação, não tem nada? Não tem condição de você abrir a porta para o povo. É o que eu falo: mudaram-se os valores”.

Nota-se, nas falas, que outro lazer mal visto e não reconhecido pela população antiga, tem florescido na Vila, vivido pela nova população que hoje habita o local. Segundo um entrevistado: "Quando tem festa na igreja, ninguém vai. [...] Não tem festa 
na igreja porque o bar concentra todo mundo lá. Não tem mais lazer na Vila Holândia. A pessoa que tem um pouco mais de cultura não vai se misturar". No mesmo sentido, outro entrevistado, lamentando o fim da Associação por conta das reclamações de vizinhos quanto ao barulho do jogo de bocha, afirmou, destacando o contraste entre ruas e o perfil mais reservado da vizinhança da Rua Cerquilho: "E esse 'tropé' aqui que amanhece na rua tocando, fazendo bagunça. [...] Aí ninguém reclama. Porque na rua de lá (rua Cerquilho, onde ficava a Associação), você vai lá, você não vê ninguém na rua”. "Agora eu me pergunto, a Associação fecharam, que era do povo, e o bar, porque ninguém fecha? Que ali não tem condição humana de ter um bar”.

Segundo Maria Poggetti, antes, quando a Vila tinha ainda poucos moradores, muita coisa era feita. Por outro lado: “[...] agora que tem bastante morador, tem condomínio, não tem nada. Até as festas da igreja fracassaram" ${ }^{28}$, afirmou a entrevistada, trazendo à tona este elemento que recentemente passou a compor a paisagem local: os condomínios fechados, cujos muros são o símbolo mais explícito de segregação e do não compartilhamento de uma identidade entre os moradores do entorno e os moradores da Vila.

Uma de nossas hipóteses iniciais era a de que o intenso desenvolvimento imobiliário observado na última década no entorno da Vila Holândia estaria expropriando espaços antes utilizados para o lazer dos moradores. Algo que, em nossa pesquisa, confirmou-se em relação a uma prática, o futebol, rememorado com bastante vivacidade pelo entrevistado Adilson Baldin. $\mathrm{O}$ morador, pertencente à segunda geração de moradores da Vila e à primeira geração de crianças que ali cresceram, mencionou em seu relato diferentes futebóis, praticados nos terrenos vazios da Vila e do entorno, que

\footnotetext{
${ }^{28}$ Entrevista com Maria Antônia Poggetti realizada em 22/03/2011.
} 
antes abundavam e que foram gradualmente ocupados ao longo das décadas.

Segundo Adilson, pequenos jogos do tipo "rua contra rua" eram realizados em campos improvisados nos terrenos baldios da Vila Holândia, e migravam de terreno em terreno, na medida em que seus proprietários construíam casas: “conforme o pessoal vinha e construía a casa a gente mudava” ${ }^{29}$. Parques e circos, que se instalavam de tempos em tempos na Vila, foram também rememorados nostalgicamente por Adilson, e seguiam a mesma lógica de ocupação dos espaços vazios.

O "grande" futebol da Vila, organizado e vivenciado pelos mais velhos, ocorria aos finais de semana em um campo situado na "Fazenda Maluf", e era comumente seguido por banhos no "tancão", uma represa, de aproximadamente 150 metros de diâmetro, construída para armazenar a água utilizada no processo de destilação da cana de açúcar produzida na fazenda, e apropriada pelos moradores, crianças e adultos, como espaço de lazer. "Era tipo uma prainha lá, tinha até um trampolim de madeira na época. Lotava" 30 .

Conta o morador que esses jogos de futebol tinham grande repercussão. Times de Barão Geraldo, de outros bairros de Campinas e de cidades como Paulínia e Cosmópolis jogavam e, a cada três meses, um torneio era realizado. Nestas ocasiões, troféus, bolas e redes eram compradas com dinheiro arrecadado na venda de churrasquinhos e sorvetes nos dias de jogos, que se tornavam motivos para uma sociabilidade mais ampla, reunindo também as famílias dos jogadores. Adilson destacou o homem apelidado de "João Mecânico", como o principal organizador dos jogos.

O jogo começava às 14 horas. Meio dia ele estava no campo. Era o que ia correr atrás de tirar as redes, guardar. Ele que se encarregava de lavar os

\footnotetext{
${ }^{29}$ Entrevista com Adilson Baldin realizada em 20/05/2011.

${ }^{30}$ Ibid.
} 
uniformes. [...] Ele roçava o campo, sabe? E a gente, às vezes, quando ia reformar o campo, nós íamos buscar grama por aí. Então ele conseguia trator, caminhão, sabe? (Entrevista com Adilson Baldin realizada em 20 de maio de 2011).

Questionado sobre os motivos que levaram ao fim desse futebol, Adilson afirmou que com a morte dos proprietários da fazenda, os herdeiros proibiram a prática no local que, posteriormente, foi loteado para a construção de um condomínio.

Foi terrível para o pessoal aí. Porque era o único lugar em que o pessoal jogava bola, assim, né? O único espaço que tinha era esse campo do Maluf. E tiraram, porque falaram que fazia parte da fazenda. Aí o dono da fazenda morreu, aí ficou para os genros, para a nora, aí eles acabaram com a fazenda. Aí que começou, sabe? Toda aquela burocracia, pra virar o quê? O condomínio. E acabou com o divertimento da Vila (Entrevista com Adilson Baldin realizada em maio de 2011).

A tentativa, por parte de alguns frequentadores, de impedir na justiça que o espaço fosse fechado, não logrou êxito, segundo Adilson, pelo fato de o campo não ser registrado na Federação de Futebol.

O pessoal foi atrás da justiça e eles falaram: 'Eu não posso fazer nada porque não está registrado'. Se estivesse registrado na Federação de Futebol eles não poderiam ter tirado esse campo. Mas, como não é, o pessoal acabou tirando o campo e fazendo os condomínios aí. Mas era muito bom pra Vila, vou falar para você: todo o pessoal da Vila, sábado e domingo à tarde estava todo no campo, uma boa parte da Vila, para assistir ao jogo. Tinha time bom, sabe? Vinha time bom de fora (Entrevista com Adilson Baldin realizada em maio de 2011).

Sem o campo do Maluf, moradores passaram a frequentar outros locais para a prática do futebol, tais como o clube da Rhodia (somente os que trabalham na empresa), e um campo no bairro Guará. Hoje, observam-se pequenos jogos, realizados por crianças nas ruas de paralelepípedos da Vila e, segundo Adilson, a Escola Estadual Francisco Alvarez cede o espaço da quadra para a vizinhança. No entanto, dentre os 
futebóis que continuam ocorrendo na Vila, o que acontece no espaço chamado Euroamérica é o que mais parece se aproximar, em dimensão, daquele narrado por Adilson. Ele se referiu a esse espaço como um "centro de divertimento da Vila", e também como "o retrato de anos atrás" ${ }^{31}$, ressaltando, porém, a diferença de ser um espaço pago, que lucra com a tradição do futebol na Vila. "Então, lazer para a Vila hoje não tem. Se você quiser um lazer hoje, que nem meu filho vai lá, você tem que pagar para jogar lá." 32 .

A prática gratuita do futebol na Vila foi impedida com a chegada dos condomínios, e tornou-se uma prática paga e, portanto, não acessível a todos. Um interlocutor, disse a respeito dos condomínios: “o progresso chegou, mas atrapalhou. [...] Hoje o lazer da região não é metade do lazer que era antes. Hoje as crianças são presas e o futebol é pago. Nadar na lagoa hoje é proibido" 33.

\section{CONSIDERAÇÕES FINAIS}

Ao longo de todo o tempo de existência da Vila Holândia, seus moradores crianças, jovens, adultos e idosos - utilizaram e utilizam o tempo livre que possuem para os divertimentos. No entanto, as práticas de divertimento mudaram bastante ao longo do curto tempo de existência da Vila. As principais práticas que reuniam e mobilizavam seus moradores deixaram de existir, as festas, o futebol e o jogo de bocha, ocasionando mudanças nas redes de relacionamento e também o contrário, mudanças nas redes de relacionamento contribuíram para o fim de tais práticas. Essas mudanças se deram de modo imbricado, mas pudemos identificar que as mudanças nas redes de relacionamento que contribuíram para o fim desses divertimentos estão ligadas à morte

\footnotetext{
31 Ibid.

${ }^{32}$ Ibid.

${ }^{33}$ Trecho extraído de diário de campo.
} 
e à mudança de pessoas da Vila para outros locais, e ao rompimento das relações entre os moradores, que se deu em decorrência de conflitos em torno dos divertimentos.

As mudanças nas redes de relacionamento ocasionadas pelo fim dos divertimentos coletivos na Vila repercutiram sobre os próprios divertimentos, fazendo com que eles passassem a ser vividos no âmbito mais particular dos domicílios, restritos ao âmbito familiar e privado, e sobre a organização dos moradores em torno de seus interesses, que deixou de acontecer. Os desentendimentos entre os moradores, em torno do bocha e da Associação de moradores, levaram a um grande rompimento na rede de relações comunitárias locais, que se deu não pela indiferença quanto à vida comunitária, mas por ressentimentos, ódios, orgulhos, alianças e rivalidades, que conferem complexidade e especificidade ao desafio de formular e implementar ações no local.

Nossa hipótese inicial de que houve perda de espaços de lazer devido à expansão imobiliária se confirmou. A prática do futebol mudou de configuração, deixando de mobilizar toda a Vila para jogar, torcer e organizar, passando a acontecer em espaços privados, em que o poder privado é quem organiza a dinâmica do jogo.

As três práticas de divertimento tidas como as mais importantes da história da Vila por nossos interlocutores ainda hoje são objeto de interesse da população local, ao menos de parte dela, pelo lugar que elas ocupam na memória dos entrevistados. Neste sentido, ações poderiam se voltar à reconstrução dessas práticas na Vila, atendendo assim aos anseios da população local.

No entanto, tais ações não podem ser realizadas sem que se leve em conta a ampla experiência dos moradores no desenvolvimento de ações coletivas, pois eles não partem de uma situação de ignorância quanto à importância e às possibilidades de participação na vida comunitária, como poderia pressupor um grupo recém chegado ao 
lócus, dotado de boas intenções para promover o lazer e a participação cidadã, mas com pouco conhecimento acerca da realidade, das relações e das possibilidades locais, como foi o nosso caso quando lá implementamos um projeto de extensão.

Outro aspecto a ser considerado, referente ao recente "progresso" de Barão Geraldo, é a mudança do perfil populacional da Vila. Vimos que parte significativa da população chegou há pouco tempo e, além de não possuir uma história neste local, apresenta grande contraste econômico e educacional em relação aos antigos moradores, tornando-se alvo de discriminação. Tal heterogeneidade nos leva a questionar quais seriam as reais possibilidades e consequências de levarmos a cabo ações pautadas no fortalecimento de uma identidade local, por meio da reconstrução e afirmação de práticas de lazer vividas no passado, pois isso poderia culminar em uma espécie de legitimação dos moradores antigos em detrimento dos recém-chegados, acentuando ainda mais a segregação entre ambos e a exclusão destes de uma suposta "verdadeira identidade" da Vila Holândia. Mas o contrário também pode acontecer, os novos moradores podem se interessar pelas antigas práticas e, na vivência das mesmas, estabelecer relações com os antigos moradores. Uma intervenção que leve em consideração todo esse contexto poderia servir à construção de uma identidade local negociada.

Por fim, cabe enfatizar que um projeto de lazer na Vila Holândia deverá ter como conteúdo cultural não apenas as práticas locais antigas, mas também outras, contribuindo à ampliação do acesso ao patrimônio cultural, para além dos conteúdos e padrões de organização cultural com os quais as populações da Vila estão habituadas. Neste sentido, o diálogo com a cultura local, que propomos no presente trabalho, deve ser acompanhado da compreensão de que não devemos tê-la como suficiente e nem 
romantizá-la ou conferir a ela um caráter nostálgico ${ }^{34}$, mas sim, considerá-la como parte de um processo mais amplo, cujo foco é a cidadania.

\section{REFERÊNCIAS}

CALDEYRO, V. S. As cidades que desenham Barão Geraldo. 2005. $117 \mathrm{f}$. Dissertação (Mestrado) - Faculdade de Engenharia Civil, Arquitetura e Urbanismo, Universidade Estadual de Campinas, Campinas, 2005.

LANG, A. B. S. G. et al. História oral e pesquisa sociológica: a experiência do CERU. São Paulo: Humanitas, 1998.

SIMSON, O. R. M. V. Memória, cultura e poder na sociedade do esquecimento. Augusto Guzzo Revista Acadêmica, São Paulo, n. 6, p. 14-18, mai. 2003b. Disponível em: $<$ http://www.fics.edu.br/index.php/augusto_guzzo/article/view/57/63>. Acesso em: 12 ago. 2013.

\section{Endereço dos Autores:}

Flávia da Cruz santos

Rua Teresa Bonato Signori 31 - Jardim Santa Genebra II

Campinas - SP - 13084-777

Endereço eletrônico: flacruz.santos@gmail.com

Henrique Okajima Nakamoto

R. Cel. Quirino, 599, ap.111, Cambuí

Campinas - SP - 13025-001

Endereço Eletrônico: henrique.nakammoto@gmail.com

Silvia Cristina franco Amaral

Faculdade de Educação Física, CP 6134

Universidade Estadual de Campinas - UNICAMP

Avenida Érico Veríssimo, 701, Cidade Universitária Zeferino Vaz, Barão Geraldo CEP: Campinas - SP - 13083-851

Endereço Eletrônico: scfa@fef.unicamp.br

\footnotetext{
${ }^{34}$ Inclusive, o próprio uso do termo "reconstrução" em preferência ao termo "resgate", parte desta compreensão, visto que a utilidade de interpretar e fazer emergir o passado, com o objetivo de enfrentar os problemas do presente e transformar a realidade, difere do mero desejo de retorno a um passado supostamente bom, em negação ao presente.
} 